\title{
The Effect of Low-level Laser Therapy and Calendula Officinalis Linn. On Cutaneous Wound Healing in Rats
}

\author{
Diego Guimarães Openheimer ${ }^{1}$, Geraldo Magela Salomé ${ }^{2 *}$, Margarida Maria de Carvalho Resende ${ }^{2}$, Paulo Calafiori \\ Resende $^{3}$, Cibele Maria Ferreira da Silva ${ }^{4}$, Marcelo Renato Massahud Junior ${ }^{1}$, Brumo mendes ${ }^{1}$ and Lydia Masako \\ Ferreira $^{5}$ \\ ${ }^{1}$ College of Health Sciences, Sapucaí Valley University (UNIVÁS), Brazil
}

${ }^{2}$ Professional master's Program in Applied Health Sciences, College of Health Sciences, Brazil

${ }^{3}$ College of Health Sciences, Sapucaí Valley University (UNIVÁS), Brazil

${ }^{4}$ College of Health Sciences, UNIVÁS, Brazil

${ }^{5}$ Full Professor at the Division of Plastic Surgery, Federal University of São Paulo (UNIFESP), Brazil

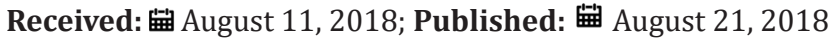

*Corresponding author: Geraldo Magela Salomé, Professional Master's Program in Applied Health Sciences, College of Health Sciences, Brazil

\begin{abstract}
Objective: To evaluate the effects of low-level laser therapy and extract of Calendula officinalis Linn. (calendula), alone or in combination, on cutaneous wound healing in rats.

Setting: A university research center.

Design: A prospective, interventional, randomized, controlled experimental study. Forty-eight female Wistar rats, aged 3 to 4 months, were divided into 4 groups of 12 animals each. A skin wound was surgically made in the dorsal region of each animal and treated for 21 days with either low-level laser therapy (laser group), calendula extract gel (calendula group), laser therapy combined with calendula extract gel (laser + calendula group) or received no treatment (control group). Data collection was performed immediately after surgery and on postoperative days $3,6,9,12,15$, 18 and 21.
\end{abstract}

Main Outcome Measures: Measurement of the wound area was performed by tracing the contour of the wound on a sterile polypropylene film placed over the wound. The drawing was transferred to the Auto Cad software to determine the size of the wound area.

Results: No significant differences in wound area size were found among groups up to the postoperative day 6. After 9 days of treatment, the laser group showed a significantly greater reduction in wound area compared to the other groups

Conclusion: Laser therapy alone contributed more to wound healing in rats than the treatment with calendula extract gel alone or combined with laser therapy.

Keywords: Laser; Calendula Officinalis; Healing; Surgical Wound

Summary

The effects of low-level laser therapy and extract of Calendula officinalis Linn. (calendula), alone or in combination, on cutaneous wound healing in rats were evaluated in 48 Wistar rats. Low-level laser therapy alone contributed more to wound healing in rats than the treatment with calendula extract, alone or in combination. The effect of low-level laser therapy and extract of Calendula officinalis Linn. on cutaneous wound healing in rats

\section{Introduction}

Low-level laser therapy (LLLT) has the potential of improving healing and reducing pain, inflammation, and edema, but its fundamental mechanisms are still not completely understood $[1,2]$. A systematic review examining the effect of LLLT on wound healing in rats found a reduction in inflammatory response and improvement in the organization of collagen fibers in the group irradiated with laser light, obtaining good results in tissue repair
[3]. LLLT has been reported as an effective tool for treating ischemic flaps, but the mechanisms of action still remain unclear [4]. Calendula officinalis Linn. (calendula), probably native to Europe, is popularly known as marigold, pot marigold, and garden-marigold [5]. The plant flowers annually and the leaves and stems are used for therapeutic purposes [6,7]. Calendula is used as an antiinflammatory, anti-tumor agent, and stimulates human mast cells 
[8]. It has healing properties, antiseptic action, sudorific effect, and analgesic, anti-inflammatory, antiviral, vessel dilator, and skin tonic activities. In addition to these benefits, the stems of calendula have antioxidant properties and studies have report that it can reduce free radicals produced in the human body [8].

The main uses of calendula are remedies for burns, bruises, skin and internal inflammatory diseases of different etiologies. The recommended doses depend on the type and severity of the illness to be treated and the individual condition of each patient [9]. Some experimental studies have obtained positive results using a combination of phytotherapic agents with other practices for treating wounds $[10,11]$. An in vitro study combining LLLT and calendula also found a positive correlation between the two [12]. The aim of the present study was to evaluate the effect of $904 \mathrm{~nm}$ low-intensity laser irradiation and extract of calendula, alone or in combination, on the healing process of skin wounds in rats.

\section{Methods}

This is a primary, interventional, prospective, analytical, controlled, randomized experimental study with rats, approved by the Institutional Ethics Committee on animal use under report number 188/2013, in accordance with the ethical principles of the Brazilian Society of Laboratory Animal Science, SBCAL/ COBEA. The sample consisted of 48 young adult, female Wistar rats, aged 3 to 4 months, distributed into the following 4 groups of 12 animals each: low-intensity GaAs laser Group (904 nm at $4 \mathrm{~J} /$ cm2), 20\% Calendula extract Group, Laser + Calendula Group, and Control Group (without treatment).The rats were anesthetized by intramuscular injection of ketamine hydrochloride at $1 \mathrm{mg} / 100 \mathrm{~g}$ and xylazine hydrochloride at $2 \mathrm{mg} / 100 \mathrm{~g}$ before making a circular wound in the dorsal region. Manual epilation was performed before placing the rats in a prone position on the operating table. The dorsum was marked with a 2.13-mm diameter stainless steel punch with a circular cutting surface. To produce the wound, a scalpel was used to make an incision and resection of the skin and panniculus carnosus up to the superficial muscular fascia.
The low-intensity laser pulse Diamond Line device and the GaAs pen laser ( $904 \mathrm{~nm}$ ) with invisible red beam, power of $30 \mathrm{~mW}$, and energy density of $4 \mathrm{~J} / \mathrm{cm}^{2}$ were used to treat the Laser Group. The laser was applied specifically on the borders of the wound at a 90-degree perpendicular angle. The wound was visually divided into a $1-\mathrm{cm}^{2}$ grid and each area of $1 \mathrm{~cm}^{2}$ received one application at each point for 12 seconds. After the application, the wound was dressed. The calendula extract gel was prepared at a local pharmaceutical laboratory. The extract consisted of $20 \%$ of glycolytic extract, $80 \%$ of Carbopol gel ( $100 \mathrm{mg}$ ) at alkaline $\mathrm{pH}$. A dose of $0.2 \mathrm{~g}$ of the extract was aspirated with a 1-ml syringe and applied and spread on the entire wound. After application of the Calendula extract, the wound was dressed. Both the laser and the calendula extract were used in combination in the Laser + Calendula Group. However, the laser was applied before the Calendula extract, following same protocols described in the other two groups. For the treatment of Control Group, we used $100 \%$ of Carbopol gel with a dose of $0.2 \mathrm{~g}$ of gel, following the same protocol as in the Calendula Group.

In all groups, the wound dressing consisted of the application of a sterile transparent adhesive film (Smith \& Nephew ${ }^{\circledR}$, model Opsite Flexigrid) measuring 4.0 x $5.0 \mathrm{~cm}$ [13]. Data collection was performed at eight time points, following the progress of treatment. The first evaluation was conducted immediately after the surgical procedure to obtain the accurate wound measurement at baseline. After that, the other evaluations occurred at three-day intervals, that is, on days $3,6,9,12,15,18$ and 21 . The animals received no treatment on postoperative day 21 , but the wound condition was evaluated, and they were then anesthetized and euthanized [14]. The measurement of the wound area was performed by tracing the perimeter of the wound using a sterile polypropylene film placed over the wound and the borders of the wound were traced using a fine-tip brush and indelible ink. These measurements were transferred to the computer program Auto Cad to quantify the wound area. For statistical analysis, the following tests were used: Kruskal-Wallis test, Friedman's test, Delta percent change (Delta\%), and Mann-Whitney test. All statistical tests were performed at a significance level $\alpha$ of $0.05(\mathrm{P}<0.05)$.

Table 1: Comparison of regression rate of wound area $\left(\mathrm{cm}^{2}\right)$ among groups $(\mathrm{n}=12)$ at evaluation intervals.

\begin{tabular}{|c|c|c|c|c|c|c|c|c|c|}
\hline \multirow{2}{*}{$\begin{array}{c}\text { Treatment } \\
\text { day \# }\end{array}$} & \multicolumn{2}{|c|}{ Calendula } & \multicolumn{2}{|c|}{ Laser } & \multicolumn{2}{c|}{ Laser + Calendula } & \multicolumn{2}{c|}{ Control } \\
\cline { 2 - 10 } & Mean & $\boldsymbol{\Delta} \%$ & Mean & $\boldsymbol{\Delta} \%$ & Mean & $\boldsymbol{\Delta} \%$ & Mean & $\boldsymbol{\Delta} \%$ & P-value \\
\hline Baseline & 2.63 & 0 & 2.54 & 0 & 2.59 & 0 & 2.57 & 0.8775 \\
\hline 3 & 2.11 & 19.77 & 2.22 & 12.59 & 2.12 & 18.14 & 1.99 & 22.56 & 0.2735 \\
\hline 6 & 1.75 & 33.46 & 1.91 & 24.80 & 1.78 & 31.27 & 1.77 & 31.12 & 0.5491 \\
\hline 9 & 1.37 & 47.90 & 1.18 & 53.54 & 1.41 & 45.55 & 1.41 & 45.13 & $0.0130^{*}$ \\
\hline 12 & 1.06 & 59.69 & 0.86 & 66.14 & 1.16 & 55.21 & 1.19 & 53.69 & $0.0013^{*}$ \\
\hline 15 & 0.85 & 67.68 & 0.45 & 82.28 & 0.88 & 66.02 & 0.99 & 61.47 & $<0.0001^{*}$ \\
\hline 18 & 0.64 & 75.66 & 0.24 & 90.55 & 0.71 & 72.58 & 0.70 & 72.76 & $<0.0001^{*}$ \\
\hline 21 & 0.40 & 84.79 & 0.03 & 98.81 & 0.54 & 79.15 & 0.55 & 78.59 & $<0.0001^{*}$ \\
\hline
\end{tabular}

Note: $\Delta \%=$ Delta percent change. Asterisks $\left(^{*}\right)$ indicate statistical significance; Kruskal-Wallis test $(\mathrm{P}<0.05)$. 


\section{Results}

Table 1 shows the mean values of the wound area of each group and the healing rate on each evaluation day. We found no differences among the groups between the initial evaluation and on days 3 and 6 , showing that the evolution of wound healing was similar for all treatments. After day 9, the Laser Group showed significant improvement in comparison with the other treatment groups, a difference that became more evident at the end of treatment. (Table 2) shows the comparisons of mean, median and standard deviation of the wound areas among the Laser, Laser + Calendula, and Control Groups. Significant treatment difference was observed on postoperative day 9 as the group treated with the laser showed faster healing than the other two groups. (Table 3) shows the comparisons of mean, median and standard deviation among the Calendula, Laser + Calendula, and Control Groups. The Calendula Group showed improvement on day 21 when compared with the group treated with Laser + Calendula, but improvement was not significant when compared with the Control Group. (Table 4) shows the comparison of Laser + Calendula and Control Groups. Both treatments were similar at all evaluation phases and no difference was found between the two groups, that is, the result of combining the two treatments is the same as using no treatment. (Table 5) shows the comparison between the Laser and Calendula Groups, and the results were similar to those in Tables 1 and Table 2 , showing the effectiveness of the laser after day 9 in comparison with the Calendula Group.

Table 2: Comparison of mean, median, standard deviation of wound areas $\left(\mathrm{cm}^{2}\right)$ among the Laser, Laser + Calendula, and Control groups $(\mathrm{n}=12)$.

\begin{tabular}{|c|c|c|c|c|c|c|c|c|c|c|}
\hline \multirow{2}{*}{$\begin{array}{l}\text { Treatment } \\
\text { day \# }\end{array}$} & \multicolumn{3}{|c|}{ Laser } & \multicolumn{3}{|c|}{ Laser + Calendula } & \multicolumn{3}{|c|}{ Control } & \multirow[b]{2}{*}{ P-value } \\
\hline & Mean & Median & SD & Mean & Median & SD & Mean & Median & SD & \\
\hline Baseline & 2.54 & 2.46 & 0.23 & 2.59 & 2.58 & 0.19 & 2.57 & 2.59 & 0.19 & 0.7693 \\
\hline 3 & 2.22 & 2.16 & 0.24 & 2.12 & 2.13 & 0.17 & 1.99 & 2.00 & 0.25 & 0.1433 \\
\hline 6 & 1.91 & 1.87 & 0.27 & 1.78 & 1.71 & 0.21 & 1.77 & 1.78 & 0.21 & 0.4938 \\
\hline 9 & 1.18 & 1.22 & 0.16 & 1.41 & 1.40 & 0.13 & 1.41 & 1.48 & 0.20 & $0.0058^{*}$ \\
\hline 12 & 0.86 & 0.87 & 0.17 & 1.16 & 1.16 & 0.14 & 1.19 & 1.15 & 0.20 & $0.0005^{*}$ \\
\hline 15 & 0.45 & 0.44 & 0.14 & 0.88 & 0.88 & 0.19 & 0.99 & 0.95 & 0.25 & $<0.0001^{*}$ \\
\hline 18 & 0.24 & 0.27 & 0.14 & 0.71 & 0.72 & 0.14 & 0.70 & 0.71 & 0.17 & $<0.0001^{*}$ \\
\hline 21 & 0.03 & 0.00 & 0.07 & 0.54 & 0.58 & 0.09 & 0.55 & 0.53 & 0.14 & $<0.0001^{*}$ \\
\hline
\end{tabular}

Note: SD, standard deviation. Asterisks $\left(^{*}\right)$ indicate statistical significance; Kruskal-Wallis test $(\mathrm{P}<0.05)$.

Table 3: Comparison of mean, median, and SD of wound areas $\left(\mathrm{cm}^{2}\right)$ between the Calendula and Laser groups, and Calendula and Control groups $(n=12)$.

\begin{tabular}{|c|c|c|c|c|c|c|c|c|c|c|}
\hline \multirow{2}{*}{$\begin{array}{c}\text { Treatment } \\
\text { day \# }\end{array}$} & \multicolumn{3}{|c|}{ Calendula } & \multicolumn{3}{|c|}{ Laser + Calendula } & \multicolumn{3}{|c|}{ Control } & \multirow[b]{2}{*}{ P-value } \\
\hline & Mean & Median & SD & Mean & Median & SD & Mean & Median & SD & \\
\hline Baseline & 2.63 & 2.61 & 0.24 & 2.59 & 2.58 & 0.19 & 2.57 & 2.59 & 0.19 & 0.9525 \\
\hline 3 & 2.11 & 2.20 & 0.29 & 2.15 & 2.13 & 0.17 & 1.99 & 2.00 & 0.25 & 0.3473 \\
\hline 6 & 1.75 & 1.69 & 0.21 & 1.78 & 1.71 & 0.21 & 1.77 & 1.78 & 0.21 & 0.9658 \\
\hline 9 & 1.37 & 1.39 & 0.22 & 1.42 & 1.40 & 0.13 & 1.41 & 1.48 & 0.20 & 0.8983 \\
\hline 12 & 1.06 & 1.09 & 0.23 & 1.16 & 1.16 & 0.14 & 1.19 & 1.15 & 0.20 & 0.3495 \\
\hline 15 & 0.85 & 0.77 & 0.21 & 0.90 & 0.88 & 0.19 & 0.99 & 0.95 & 0.25 & 0.3444 \\
\hline 18 & 0.64 & 0.59 & 0.20 & 0.72 & 0.72 & 0.14 & 0.70 & 0.71 & 0.17 & 0.5772 \\
\hline 21 & 0.40 & 0.40 & 0.19 & 0.54 & 0.58 & 0.09 & 0.55 & 0.53 & 0.14 & $0.0242 *$ \\
\hline
\end{tabular}

Note: SD, standard deviation. Asterisks $\left({ }^{*}\right)$ indicate statistical significance $(\mathrm{P}<0.05)$.

Table 4: Comparison of mean, median, and SD of wound areas $\left(\mathrm{cm}^{2}\right)$ between the Laser + Calendula and Control groups $(\mathrm{n}=12)$.

\begin{tabular}{|c|c|c|c|c|c|c|c|}
\hline \multirow{2}{*}{$\begin{array}{c}\text { Treatment } \\
\text { day \# }\end{array}$} & \multicolumn{3}{|c|}{ Laser + Calendula } & \multicolumn{3}{c|}{ Control } & Median \\
\cline { 2 - 8 } & Mean & Median & SD & Mean & SD & P-value \\
\hline Baseline & 2.59 & 2.58 & 0.19 & 2.57 & 2.59 & 0.19 & 0.8399 \\
\hline 3 & 2.12 & 2.13 & 0.17 & 1.99 & 2.00 & 0.25 & 0.2040 \\
\hline 6 & 1.78 & 1.71 & 0.21 & 1.77 & 1.78 & 0.21 & 0.7508 \\
\hline 9 & 1.41 & 1.40 & 0.13 & 1.41 & 1.48 & 0.20 & 0.8852 \\
\hline 12 & 1.16 & 1.16 & 0.14 & 1.19 & 1.15 & 0.20 & 0.8399 \\
\hline 15 & 0.88 & 0.88 & 0.19 & 0.99 & 0.95 & 0.25 & 0.3123 \\
\hline
\end{tabular}




\begin{tabular}{|l|l|l|l|l|l|l|l|}
\hline 18 & 0.71 & 0.72 & 0.14 & 0.70 & 0.71 & 0.17 & 0.6650 \\
\hline 21 & 0.54 & 0.58 & 0.09 & 0.55 & 0.53 & 0.14 & 0.9081 \\
\hline
\end{tabular}

Note: SD, standard deviation. Asterisks $\left(^{*}\right)$ indicate statistical significance; Mann-Whitney test $(\mathrm{P}<0.05)$.

Table 5: Comparison of mean, median, and SD of wound areas $\left(\mathrm{cm}^{2}\right)$ between the Laser and Calendula groups $(\mathrm{n}=12)$.

\begin{tabular}{|c|c|c|c|c|c|c|c|}
\hline \multirow{2}{*}{$\begin{array}{c}\text { Treatment } \\
\text { day \# }\end{array}$} & \multicolumn{3}{|c|}{ Laser } & \multicolumn{3}{|c|}{ Calendula } \\
\cline { 2 - 9 } & Mean & Median & SD & Mean & Median & SD & P-value \\
\hline Baseline & 2.54 & 2.46 & 0.23 & 2.63 & 2.61 & 0.24 & 0.4884 \\
\hline 3 & 2.22 & 2.16 & 0.24 & 2.11 & 2.20 & 0.29 & 0.5637 \\
\hline 6 & 1.91 & 1.87 & 0.27 & 1.75 & 1.69 & 0.21 & 0.1489 \\
\hline 9 & 1.18 & 1.22 & 0.16 & 1.37 & 1.39 & 0.22 & $0.0179^{*}$ \\
\hline 12 & 0.86 & 0.87 & 0.17 & 1.06 & 1.09 & 0.23 & $0.0262^{*}$ \\
\hline 15 & 0.45 & 0.44 & 0.14 & 0.85 & 0.77 & 0.21 & $<0.0001^{*}$ \\
\hline 18 & 0.24 & 0.27 & 0.14 & 0.64 & 0.59 & 0.20 & $<0.0001^{*}$ \\
\hline 21 & 0.03 & 0.00 & 0.07 & 0.40 & 0.40 & 0.19 & $<0.0001^{*}$ \\
\hline
\end{tabular}

Note: SD, standard deviation. Asterisks $\left(^{*}\right)$ indicate statistical significance; Mann-Whitney test $(\mathrm{P}<0.05)$.

\section{Discussion}

Changes in skin integrity commonly result in injuries, hinder healing and the rehabilitation process of patients, particularly in elder patients as the skin undergoes physiological changes, such as collagen changes, reduction of elastic fibers, leading to a reduction in skin thickness and epidermal and dermal elasticity. The reduction of tissues, mitosis, hormones, and vascularization delays wound healing and re-epithelialization in both humans and animals [15]. Wound treatment is dynamic, and it depends on each healing phase. Currently there are numerous choices of dressings and adjuvant treatments on the market, such as: new wound dressing technologies, phytotherapic treatments, hyperbaric chamber adjuvant treatments, LLLT, ultrasound, faradic current, and others [16]. Experimental studies obtained positive results using phytotherapic agents with other wound treatment procedures [13]. An in vitro study using low-intensity laser associated with calendula also showed the healing potential of this combination [17]. Another study evaluated the healing capacity of calendula on wounds in animals and the authors concluded that calendula yields satisfactory results in wound healing [18]. Another study obtained a positive result for skin wound healing but suggested further research [19].

Studies evaluating the healing potential of calendula concluded that although more collagen fibers and fibroblasts were organized in the calendula group than in the control group, but no statistically significant difference was found [20]. In the present study, the group treated with calendula extract showed a healing potential, but the results were the same as those found in the above-mentioned study in which the group treated with calendula showed no significant difference from control group (Table 3). Studies have shown that the laser is able of influencing the proliferation of fibroblasts, osteoblasts and skin cells. The laser therapy has effects on collagen and collagen synthesis [21]. Another study investigated the effects of different types of low-intensity laser on skin flaps in rats. The application of low-intensity laser showed significant results in wound healing in rats [22]. A study conducted with the aim of analyzing the healing of epithelial tissue treated with low-intensity laser with wavelength of $904 \mathrm{~nm}$ at $4 \mathrm{~J} / \mathrm{cm}^{2}$ and $8 \mathrm{~J} / \mathrm{cm}^{2}$ found that the dose of $4 \mathrm{~J} / \mathrm{cm}^{2}$ is more effective [23]. In another study, the researchers investigated the healing of epithelial tissue treated with low-intensity laser for 21 days with evaluations on days 7, 14 and 21.

That study found little difference on day 7 of evaluation in comparison with control group and the difference was more significant on days 14 and 21, indicating the effectiveness of lowintensity laser [23]. In the present study we used low-intensity laser with wavelength of $904 \mathrm{~nm}$ at $4 \mathrm{~J} / \mathrm{cm}^{2}$ and significant results were obtained when compared with the other groups. We found a significant difference after day 9 and up to day 21. These data are similar to those found in the literature (Table 1). In a study to compare the effect of low-intensity laser on circular wounds in rats, it was concluded that low-intensity laser treatment is easy to apply, safe and cost effective for surface wounds [24]. The present study also made surgically performed circular wounds in the dorsum of rats and found that low-intensity laser was successful for this type of injury, which corroborates the data found in the mentioned study (Table 2). Another study evaluated the effect of low-intensity laser with wavelength of $904 \mathrm{~nm}$ on the healing of surgical wounds in rats and concluded that low-intensity laser reduced the intensity of the inflammatory reaction and influenced the dynamics of the immune response by inducing change in the infiltration pattern of leukocytes, stimulating deposition, and improving the organization of the collagen fibers.

The low-intensity laser with wavelength of $904 \mathrm{~nm}$ was effective in the treatment of surgical wounds in rats [25]. The authors of a study that compared two types of LLLT, the GaAs and HeNe laser, on wound healing concluded that the GaAs laser showed better results, thus confirming its potential to heal wounds [26]. In a 
review conducted to investigate experimental irradiation studies using LLLT on wound healing in rats, the authors concluded that studies suggest a dose of $4 \mathrm{~J} / \mathrm{cm}^{2}$ for wound treatments and their findings strongly support the use of laser for human therapy [27]. The present study used the same protocols used in previous studies [25-27]. With regard to the type of low-intensity laser used and dose applied and found results that are consistent with the literature.

\section{Conclusion}

The laser + calendula group showed no advantage over control group and it is not practical to treat wounds. Calendula showed a significant result in relation to the laser + calendula group on the last day of treatment evaluation. LLLT showed significant results after 9 days of treatment in comparison with the other groups, confirming that it is the best kind of treatment for this type of wound. Low-intensity laser was the best treatment among the groups as significant results were obtained, which proves that it is the most effective treatment and the easiest to apply.

\section{References}

1. Prindeze NJ, Moffatt LT, Shupp JW (2012) Mechanisms of action for light therapy: a review of molecular interactions. Exp Biol Med (Maywood) 237: 1241-1248.

2. Chen AC, Arany PR, Huang YY (2011) Low-level laser therapy activates NF-kB via generation of reactive oxygen species in mouse embryonic fibroblasts. PLoS One 6: e22453.

3. Leal CT, Bezerra AL, Lemos A (2013) Effectiveness of HeNe $632.8 \mathrm{~nm}$ laser on skin tissue integrity repair in experimental animals: a systematic review. Fisioter Pesqui 19: 290-296.

4. Esteves I, Masson IB, Oshima CT, Paiotti AP, Liebano RE, et al. (2012) Low-level laser irradiation, cyclooxygenase-2 (COX-2) expression and necrosis of random skin flaps in rats. Lasers Med Sci 27: 655-660.

5. Serra AP, Marchetti ME, Vieira MC (2013) Nitrogen nutritional efficiency and biomass production in Calendula officinalis L. (Asteraceae) under greenhouse conditions. Rev Bras Plantas Med 15: 78-85.

6. Parente LM, Lino Júnior Rde S, Tresvenzol LM, Vinaud MC, Paulo NM, et al. (2012) Wound healing and anti-inflammatory effect in animal models of Calendula officinalis L. growing in Brazil. Evid Based Complement Alternat Med 2012: 375671.

7. Saini P, Al-Shibani N, Sun J (2012) Effects of Calendula Officinalis on human gingival fibroblasts. Rev Homeopathy 101: 92-98.

8. Fonseca YM, Catini CD, Vicentini FT, Nomizo A, Gerlach RF, et al. (2010) Protective effect of Calendula officinalis extract against UVB-induced oxidative stress in skin: Evaluation of reduced glutathione levels and matrix metalloproteinase secretion. J Ethnopharmacol 127: 596-601.

9. Mendonça AMS, Pádua M, Ribeiro AP, Milani GB, João SMA, et al. (2009) Intra and inter-examiner reliability of photogrammetry in the classification of the degree of gynoid lypodystrophy in asymptomatic women. Fisioter Pesqui 16: 102-106.

10. Semenoff Segundo A, Bosco AF, Maia D (2007) The influence of Aloe vera and propolis in the contraction of wounds on dorsal area of rats. Periodontia 17: 23-28.

11. Mendonça FA, Passarini Junior JR, Esquisatto MA, Mendonça JS, Franchini CC, et al. (2009) Effects of the application of Aloe vera (L.) and microcurrent on the healing of wounds surgically induced in Wistar rats. Acta Cir Bras 24: 150-155.
12. Bresler A, Hawkins D, Razlog R, Abrahamse H (2007) Effect of low level laser therapy and Calendula officinalis $3 \mathrm{CH}$ on wound healing in human skin fibroblasts. Am J Homeopat Med 100:110-118.

13. Wolcott RD, Rumbaugh KP, James G (2010) Biofilm maturity studies indicate sharp debridement opens a time-dependent therapeutic window. J Wound Care 19: 320-328.

14. Nordback PH, Miettinen S, Kääriäinen M, Pelto-Huikko M, Kuokkanen H, et al. (2012) Amniotic membrane reduces wound size in early stages of the healing process. J Wound Care 21: 190-197.

15. Salomé GM, Openheimer DG, de Almeida SA, Bueno ML, Dutra RA, et al. (2013) Feelings of powerlessness in patients with venous leg ulcers. J Wound Care 22: 628-634.

16. De Abreu MF, Fagundes DS (2011) Ação da irradiação laser de baixa frequência (LLLT) sobre os mecanismos celulares envolvidos na reparação de tecido nervoso periférico [Action of low frequency laser irradiation (LLLT) on the cellular mechanisms involved in the repair of peripheral nervous tissue]. Rev Cie Fac Edu Mei Amb 2: 80-96.

17. Ribeiro G, Silva MAG, Martins CB, Borges JC, Lacerda Neto JC, et al. (2013) Herbal combination in the treatment of equine skin induced wounds. Arq Bras Med Vet Zootec. 65: 1427-1433.

18. Nitz AC, Ely JB, d'Acampora AJ, Tames DR, Corrêa BP (2006) Estudo morfométrico no processo de cicatrização de feridas cutâneas em ratos, usando: Coronopu didymus e Calendula officinali [Morphometric study in the process of wound healing in rats using Coronopus didymus and Calendula officinalis]. Arq Catarinenses Med 35: 74-79.

19. De Oliveira Guirro EC, de Lima Montebelo MI, de Almeida Bortot B, da Costa Betito Torres MA, et al. (2010) Effect of laser $(670 \mathrm{~nm})$ on healing of wounds covered with occlusive dressing: a histologic and biomechanical analysis. Photomed Laser Surg 28: 629-634.

20. Chung TY, Peplow PV, Baxter GD (2010) Laser photobiomodulation of wound healing in diabetic and non-diabetic mice: effects in splinted and unsplinted wounds. Photomed Laser Surg 28: 251-61.

21. Busnardo VL, Biondo-Simões ML (2010) Effects of low-level heliumneon laser on induced wound healing in rats. Rev Bras Fisioter 14: 4551.

22. Baldan C, Pasqual AM, Schiavinato AM, Casarotto RA (2010) Dosedependência do laser de baixa intensidade $(670 \mathrm{~nm})$ na viabilidade de retalhos cutâneos randômicos em ratos [Dose-dependency of LLLT on the viability of random skin flaps in rats]. J Health Sci Inst 28: 359-362.

23. Abreu JAC, Souza AL, Alves CLGF, Nunes JT, et al. (2011) Histological analysis of experimental wound healing under the action of low power laser. Sci Med 21: 96-100.

24. Adamskaya N, Dungel P, Mittermayr R (2011) Light therapy by blue LED improves wound healing in an excision model in rats. Injury 42: 917921.

25. Melo VA, Anjos DC, Albuquerque Júnior R, Melo DB, Carvalho FU, et al. (2011) Effect of low level laser on sutured wound healing in rats. Acta Cir Bras 26: 129-134.

26. Sanati MH, Torkaman G, Hedayati M, Dizaji MM, et al. (2011) Effect of Ga-As $(904 \mathrm{~nm})$ and He-Ne $(632.8 \mathrm{~nm})$ laser on injury potential of skin full-thickness wound. J Photochem Photobiol B 103: 180-185.

27. Peplow PV, Chung TY, Baxter GD (2010) Laser photobiomodulation of wound healing: A review of experimental studies in mouse and rat animal models. Photomed Laser Surg 28: 291-325. 
ISSN: 2574-1241

DOI: 10.26717/BJSTR.2018.08.001616

Geraldo Magela Salomé. Biomed J Sci \& Tech Res

(c) (P) This work is licensed under Creative

Submission Link: https://biomedres.us/submit-manuscript.php

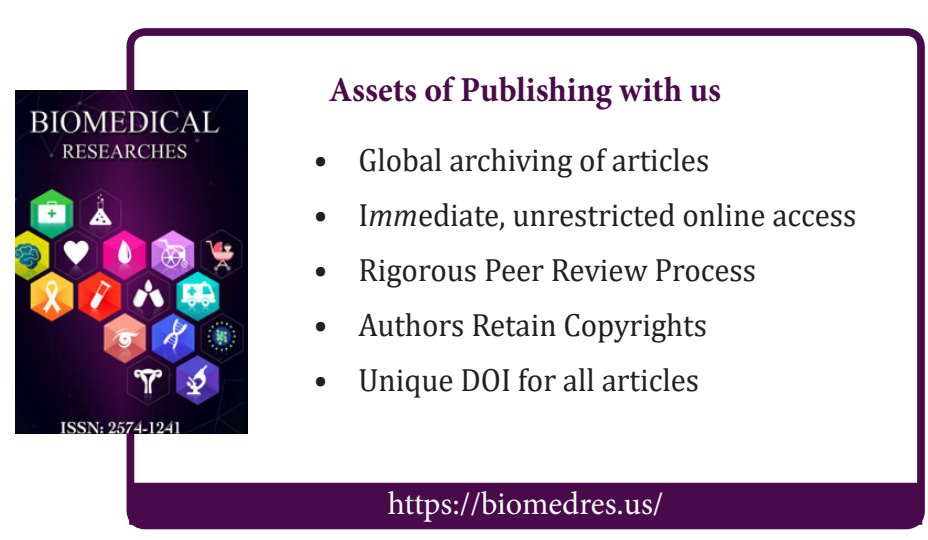

